\title{
La ópera tras la contienda: La soprano Mercedes Capsir y el renacer del Gran Teatro del Liceo de Barcelona tras la Guerra Civil Española (1939)
}

\author{
Opera after Contend: The Soprano Mercedes Capsir and the \\ Rebirth of Gran Teatro del Liceo in Barcelona after the Spanish \\ Civil War (1939)
}

\author{
Virginia Sánchez Rodríguez \\ Universidad de Castilla-La Mancha \\ Centro de Investigación y Documentación Musical, \\ Unidad Asociada al Consejo Superior de Investigaciones Científicas (España) \\ virginia.sanchez@uclm.es
}

\begin{abstract}
Resumen
Probablemente el nombre de Mercedes Capsir (1897-1969) no sea especialmente recordado en la actualidad, a pesar de las numerosas investigaciones sobre ópera realizadas en las últimas décadas. Sin embargo, no solo fue una de las sopranos de coloratura más célebres de su época, con presencia en Europa y América, sino que Capsir también ha pasado a la historia por haber participado en la primera función celebrada en el Gran Teatro del Liceo de Barcelona una vez finalizada la Guerra Civil Española, en el año 1939. En este trabajo ofrecemos un reconocimiento a la soprano, así como una profundización al mencionado acontecimiento histórico, caracterizado por la calidad artística de sus participantes y por la significativa carga ideológica del mismo.
\end{abstract}

\section{Palabras Clave}

Mercedes Capsir; Guerra Civil Española; Gran Teatro del Liceo; Barcelona; mujeres músicas.

\begin{abstract}
Probably the name of Mercedes Capsir (1897-1969) is not especially remembered today, despite the numerous studies about opera carried out in recent decades. She was one of the most famous coloratura sopranos of her time, with presence in Europe and America, and Capsir has also gone down in history for having participated in the first function held at the Gran Teatro del Liceo in Barcelona once the Spanish Civil War ended, in 1939. In this paper we offer recognition to Mercedes Capsir and a study of the aforementioned historical event, characterized by the artistic quality of its participants and by its significant ideological meaning.
\end{abstract}

\section{Keywords}

Mercedes Capsir; Spanish Civil War; Gran Teatro del Liceo; Barcelona; Women in Music.

Esta obra está sujeta a la Licencia Reconocimiento-NoComercial-CompartirIgual 4.0 Internacional de Creative Commons. http://creativecommons.org/licenses/by-nc-sa/4.0/ 


\section{Virginia Sánchez Rodríguez}

\section{Introducción}

Las mujeres artistas, a día de hoy, aún no ocupan el espacio merecido en la historiografía. Un ejemplo de ello lo representa la soprano española Mercedes Capsir (1897-1969), quien, hasta el momento, es tan solo la protagonista de un pequeño acercamiento monográfico en lengua catalana (Tanzi Capsir, 2002) y ocupa escasas líneas en las entradas de diccionarios de historia general (Heilbron, s.f.) o de historia de la música (Celetti, 1992; Casares, 2002). Asimismo, y aunque su nombre apareció en las mejores críticas de la época y todavía acaparó espacio en la prensa especializada tras su fallecimiento (Lauri-Volpi, 1974, p. 4; Fernández-Cid, 1974, pp. 26-27; Hernández Girbal, 1988, p. 109; Badenes, 1994, pp. 50-51;), es solamente mencionado, de forma escueta, en algunas fuentes secundarias (Martínez del Campo Saucedo, 1998, p. 431; Piñero, 2004, p. 398).

A pesar de esta realidad, lo cierto es que Capsir, como otras grandes féminas del pasado, fue una de las protagonistas de algunos eventos culturales paradigmáticos de la historia contemporánea. De acuerdo con esta realidad, en el presente trabajo se profundiza en la primera función programada en el Gran Teatro del Liceo de Barcelona tras la finalización de la Guerra Civil Española, un evento celebrado en 1939, tan solo unos días después del fin de su desenlace. En concreto, esta investigación nace con la intención de conocer cómo se gestó la producción, cómo fue la acogida por parte del público -deseoso de que volviera a resplandecer el coliseo catalán- y por qué se seleccionó a Mercedes Capsir -y no a otra sopranopara protagonizar este evento.

Para llevar a cabo la investigación, además del correspondiente acceso a fuentes secundarias de carácter bibliográfico, se ha tomado como núcleo una selección de fuentes primarias de carácter institucional y hemerográfico coetáneas al acontecimiento estudiado. Junto a la documentación procedente del Archivo Histórico del Gran Teatro del Liceo de Barcelona (Arxiu Històric de la Societat del Gran Teatre del Liceu) y al material gráfico de una colección privada, las fuentes hemerográficas cobran un protagonismo especial de acuerdo con la escasez de fuentes primarias en torno a las figuras femeninas ${ }^{1}$ vinculadas al arte en los siglos pasados. En concreto, como se expondrá a lo largo del artículo, hemos acudido a $L a$ Vanguardia Española en exclusiva debido a que es el único medio de alcance nacional que referenció esta "Extraordinaria función benéfico-patriótica" del Liceo, que, como señalaremos, se produjo en una fecha muy próxima a la finalización del conflicto bélico.

\footnotetext{
${ }^{1}$ En parte, esa ausencia de fuentes primarias tiene que ver con la limitada profesionalización musical femenina: "La escasa profesionalización de las mujeres de otras épocas con talento musical repercute, por otra parte, en la exigüidad y dispersión de las fuentes que testimonian sus actividades musicales, constituyendo una de las principales dificultades para la escritura de una historia anterior a 1900" (Ramos López, 2013, p. 220).
} 


\section{La ópera tras la contienda: La soprano Mercedes Capsir y el renacer del Gran Teatro del Liceo de Barcelona tras la Guerra Civil Española (1939)}

\section{El año 1939 y la nueva etapa del Gran Teatro del Liceo}

El 1 de abril de 1939, tras tres años de contienda, el militar Francisco Franco (18921975) firmó el último parte de guerra, proclamando su victoria e iniciando un régimen dictatorial que se extendió hasta el 20 de noviembre de 1975, fecha de su fallecimiento. Es así como comienza “la era de Franco” (Tamames, 1981), pues “iqué otro nombre podríamos haber escogido si no ha habido una época en toda nuestra historia marcada de forma tan indeleble por una figura política individual como lo fueron los treinta y seis años del franquismo?" (p. 331).

La Guerra Civil, surgida por el alzamiento del bando nacional o sublevado ante la II República Española, sumió al país en un lamentable escenario que se cobró la vida de más de medio millón de personas, provocó un profundo deterioro socioeconómico y paralizó la cultura, una penosa situación que se extendió los años posteriores. Una vez finalizado el conflicto, la ciudad de Barcelona -que, junto con los daños de su población, también resultó muy castigada desde el punto de vista arquitectónico $^{2}$ - trató de recuperarse y erigirse como lo que siempre fue: un referente en la cultura, en las artes y en la música ${ }^{3}$, disciplina protagonista de este trabajo.

Sin embargo, incluso durante el tiempo en que el conflicto se extendió, la ciudad condal continuó con cierto movimiento en los centros escénicos más destacados, como el Palacio de la Música Catalana, el Teatro Tívoli, el Teatro Olimpia, el Palacio de Bellas Artes -donde, principalmente, se ofrecían conciertos matutinos los domingos- y también el Gran Teatro del Liceo. Marco Antonio de la Ossa Martínez (2009) expone, con detalle, la situación musical de Barcelona durante la guerra. En ese contexto, uno de los recintos más destacados fue el $\mathrm{Liceo}^{4}$, especialmente desde 1938:

\footnotetext{
"Barcelona fue un importante centro musical, debido en gran parte a que el frente de guerra quedó establecido lejos de la ciudad. El Teatro del Liceo, pese a que se mantuvo cerrado la mayor parte del conflicto, se convirtió en uno de los centros musicales más importantes (...).

Las puertas del Liceo se cerrarán poco antes del estallido de la guerra civil. Previamente, en la temporada 1935-36 tuvo lugar la representación de una
}

\footnotetext{
2 Para una profundización sobre este aspecto, véase Arañó \& Capdevila, 2019.

3 Desde finales del siglo XIX, especialmente desde la Exposición Universal de 1888, Barcelona fue pionera en las novedades relativas a la música de concierto -basta pensar, tan solo en el legado compositivo de Isaac Albéniz (1860-1909) y Enrique Granados (1867-1916), entre otros-, a la música ligera -la ciudad condal fue una receptora privilegiada de los ritmos del momento llegados desde el extranjero y también acogió la producción de artistas como Clifton Worsley (1873-1925) (Ezquerro Esteban \& Ezquerro Guerrero, 2018, pp. 5-98; Ezquerro Esteban \& Ezquerro Guerrero, 2019, pp. 161-232)- y también desarrolló una intensa actividad editora, pues Barcelona es "ciudad con unos antecedentes en el ámbito de la edición musical bastante meritorios" (Ezquerro Esteban, 2020, p. 109).

4 Para una profundización sobre la historia del Gran Teatro del Liceo de Barcelona, véanse: Alier Axiala 1986; Alier Axiala 1990; Alier Axiala 1994; Radigales 1998; Radigales 1999; Alier Axiala 2011.
} 


\section{Virginia Sánchez Rodríguez}

Tetralogía completa de Richard Wagner bajo la dirección de Kart Elmendorff (...)

El Teatro del Tívoli tomará entonces la iniciativa operística barcelonesa desde septiembre de 1936 hasta mayo de 1937, fecha en que la compañía residente se trasladará al Teatro Olimpia, sala en la que se ofrecieron un puñado de funciones (...).

La reapertura del Liceo en 1938 y el traslado del gobierno republicano desde Valencia a Barcelona recuperó en parte la actividad de la mítica sala catalana, cortada en muchos casos por bombardeos y ataques de la aviación franquista. El público distaba mucho del que se podía ver en años anteriores, ya que se componía de miembros del gobierno, funcionarios, militares e intelectuales. Las propuestas presentadas dejaron a un lado las producciones alemanas e italianas y se centraron en óperas, zarzuelas y ballets" (Ossa Martínez 2009: 133-135).

Construido con fondos privados en La Rambla de Barcelona, fruto de las aportaciones particulares de accionistas tras la configuración de la Sociedad del Gran Teatro del Liceo en 18375, el edificio original se inauguró el día 4 de abril de 1847. Desde entonces, y a pesar de sufrir un incendio en el año 1861 y del atentado anarquista de 1893, la actividad del espacio escénico fue bastante constante, incluso durante la conflagración, a pesar de su cambio de titularidad.

Con el estallido de la guerra, el coliseo fue expropiado por la Generalitat de Catalunya ${ }^{6}$ y denominado desde ese momento Teatre Nacional de Catalunya. Fue en 1939 cuando el Régimen devolvió el espacio teatral a sus propietarios originales -la mencionada Sociedad del Gran Teatro del Liceo-, recuperó su nombre inicial y se empezó a pensar en restablecer la actividad operística a un ritmo similar al que se disfrutaba justo antes de la contienda.

Incluso antes de la proclamación oficial del fin del conflicto, ya se empezaron a llevar a cabo algunas acciones para que el teatro volviera a acoger, cuanto antes, las producciones escénicas para las que, originalmente, había sido erigido. La primera de esas iniciativas fue la convocatoria de la primera Junta de Gobierno de la Sociedad del Gran Teatro del Liceo después de la guerra, prevista para el día 6 de marzo de 1939 y anunciada en el diario La Vanguardia Española ${ }^{7}$ del siguiente modo:

\footnotetext{
5 "Los inicios del Gran Teatre del Liceu datan de 1837 cuando un batallón de la Milicia Nacional, bajo la iniciativa de Manuel Gibert, creó en el desafectado convento de Montsió (actual portal del Ángel) el núcleo institucional del futuro Teatre: una sociedad dramática de aficionados dedicados a las artes escénicas". Gran Teatro del Liceo. Recuperado de https://www.liceubarcelona.cat/es/el-gran-teatredel-liceu

6 “Esta nacionalización se concretó en el Decreto del 27/07/1936 mediante el cual el Liceu pasaba a llamarse Teatre Nacional de Catalunya. Tres días más tarde, en los bajos del Círculo del Liceo se instaló la Comisaría de Espectáculos de la Generalitat y el 5 de agosto de 1936 se redactó un anexo al decreto quedando nacionalizado, también, el Círculo y el Conservatorio". Gran Teatro del Liceo. Recuperado de https://www.liceubarcelona.cat/es/el-gran-teatre-del-liceu

7 El diario La Vanguardia, editado en Barcelona desde 1881 y hasta la actualidad, se denominó La Vanguardia Española entre 1939 -con la finalización del conflicto bélico y el comiendo del franquismo- y 1978 -fecha en la que ya estaba establecida la Democracia y se produjo la promulgación de la Constitución Española, todo ello tras la finalización del régimen de Francisco Franco en 1975-. Se trata de un medio generalista de tirada nacional.
} 


\title{
La ópera tras la contienda: La soprano Mercedes Capsir y el renacer del Gran Teatro del Liceo de Barcelona tras la Guerra Civil Española (1939)
}

\author{
"La Junta de Gobierno convoca la General Extraordinaria de señores \\ Accionistas, para mañana lunes, día 6 del corriente, a las cinco de la tarde, en el \\ Salón de Descanso de este Gran Teatro, con el objeto de tratar: \\ $1 \stackrel{0}{\circ}$. Futuro de este Teatro. \\ $2^{\circ}$. Estado económico. \\ La Junta General quedará legalmente constituida media hora después de la \\ señalada, cualquiera que sea el número de concurrentes, y sus acuerdos serán \\ obligatorios para todos los señores Accionistas. \\ Barcelona, 5 de marzo de 1939 \\ III Año Triunfal. \\ P. A. de la J. de G. \\ El Vocal Delegado. \\ Antonio Mercader Brunet" (La Vanguardia Española, Barcelona, 05/03/1939, \\ p. 4).
}

La Junta había sido convocada "para tratar del futuro económico del Gran Teatro y del estado económico del mismo" (La Vanguardia Española, Barcelona, 08/03/1939, p. 3). El acto fue presidido por Antonio Mercader Brunet, el vocal delegado, y asistieron los accionistas más destacados, la mayor parte de ellos empresarios,

"como los señores Pons Arola, Clot Junoy, don Miguel Casals, don Antonio de Ferrater, doña María Llorach, don Santiago Güell, doña Esperanza Masana, viuda de Morera: don José Borrell y Sol, don Francisco J. Vila, don Luis Coromina, don Eusebio Carreras, don José Valls y Taberner y el empresario y accionista don Juan Mestres" (La Vanguardia Española, Barcelona, 08/03/1939, p. 3).

En la reunión, tras un homenaje a los miembros de la Junta fallecidos en los últimos años -bien por el conflicto bélico, bien por circunstancias naturales-, se trataron aspectos económicos, pero también cuestiones artísticas. Uno de los asuntos principales abordados tuvo que ver con el regreso del empresario teatral Joan Mestres Calvet (1871-1955), quien había sido previamente el director artístico del Gran Teatro del Liceo en las temporadas 1915-1916, 1918-1930 y 1933-1936:

\footnotetext{
"Propuso la presidencia que constara en acta el pesar de la Junta por las pérdidas expresadas, acordándose así por unanimidad.

Se adoptaron después varios acuerdos de orden interior, y se cambiaron impresiones respecto al futuro del teatro.

El empresario, don Juan Mestres, ofreció laborar cuanto pueda, en su cargo, y dar las facilidades que estén a su alcance, a fin todo ello de conseguir, de nuevo, el esplendor artístico de los mejores tiempos" (La Vanguardia Española, Barcelona, 08/03/1939, p. 3).
}

La guerra había pillado a Mestres fuera de España como parte de sus asuntos profesionales. A su regreso a Barcelona, y tras haber ejercido como comisario de Teatros Nacionales y Municipales y Conciertos en Madrid, enseguida recibió la propuesta de recuperar su anterior trabajo en el Liceo. De ello se da cuenta en $L a$ Vanguardia Española: 


\title{
Virginia Sánchez Rodríguez
}

\begin{abstract}
"Al iniciarse el período de tiranía roja en Barcelona, se hallaba en el extranjero, preparando la temporada de invierno de 1936, el empresario del Gran Teatro del Liceo, don Juan Mestres Calvet.

Desde el primer instante, todas las simpatías del señor Mestres se concentraban en la noble causa que defendía el Generalísimo. Por ello, se trasladó prontamente a la España liberada, donde ha realizado una labor eficacísima en pro del arte, tanto, que le ha valido ser nombrado comisario de Teatros Nacionales y Municipales y Conciertos.

Las hordas marxistas no eximieron de sus odios al señor Mestres, al que, si no en persona, han causado grandes daños en sus bienes, de los que le han inicuamente despojado, destruyendo -¡cómo no!- aquello que tenía un valor esencialmente artístico.

Vuelta, felizmente, Barcelona a la España Nacional, el señor Mestres ha regresado a Barcelona, donde su presencia ha sido acogida con el afecto de siempre.

Naturalmente, el señor Mestres ha sido interrogado acerca de la posibilidad de una pronta reanudación de las actividades en el Liceo. El señor Mestres no ha dado una respuesta categórica a la pregunta, limitándose a manifestar que, dada la premura del tiempo, considera difícil poder organizar para la próxima primavera una temporada en el Gran Teatro" (La Vanguardia Española, Barcelona, 07/03/1939, p. 6).
\end{abstract}

Mestres fue designado, de nuevo, director artístico del teatro tras esa primera junta. Un mes después, en abril de 1939, se celebró una segunda junta general de accionistas donde se eligió, por unanimidad, a Joaquín de Sentmenat y de Sarriera (1894-1968), marqués de Sentmenat, como presidente del Liceo ${ }^{8}$. A partir de ese momento, Mestres rápidamente comenzó a trabajar en la organización de la futura temporada 1939-1940, que se inauguró el 9 de diciembre de 1939 con la ópera Goyescas de Enrique Granados (1867-1916). Sin embargo, previamente se había reactivado la actividad artística de este espacio barcelonés tras el conflicto, sin escatimar en la que sería la apertura del teatro tras la guerra. Y para tan inauguración triunfal pensaron en la presencia sobre las tablas del Liceo de una de las sopranos barcelonesas más célebres del momento: Mercedes Capsir.

\section{Mercedes Capsir: una estrella internacional para una función histórica}

Mercedes Capsir Vidal nació en Barcelona en el año 18979, en el seno de una familia de músicos, siendo hija de un barítono y una soprano. Precisamente durante el siglo XIX, y también a lo largo del siglo XX, algunas de las féminas que lograron desarrollar una carrera profesional en la música lo hicieron, al igual que Capsir, continuando el

\footnotetext{
8 Una segunda Junta general de accionistas del Liceo un mes después, el 5 de abril de 1939, donde se eligió, por unanimidad, a don Joaquín de Sentmenat y de Sarriera (1894-1968), marqués de Sentmenat, como presidente (La Vanguardia Española, Barcelona, 05/04/1939, p. 6).

${ }^{9}$ En este trabajo nos adscribimos al año 1897 como la fecha de su nacimiento por ser la más repetida en la historiografía (Casares, 2002; Tanzi Capsir, 2002; Badenes, 2005; Heilbron, s.f.), a pesar de que otras fuentes hablan de otras fechas, como 1890 (Piñero, 2004, p. 398) y 1899 (Martínez del Campo, 1998, p. 431).
} 


\title{
La ópera tras la contienda: La soprano Mercedes Capsir y el renacer del Gran Teatro del Liceo de Barcelona tras la Guerra Civil Española (1939)
}

oficio familiar: "Muchas mujeres, la mayoría procedentes de familias de artistas o de músicos profesionales, consiguieron una carrera exitosa a principios y mediados del siglo XIX" (Lumsden, 2010, p. 918) ${ }^{10}$. Si bien es cierto que se produjo una profesionalización musical de las mujeres desde finales del siglo XVIII y durante todo el XIX, se observa una mejora en la consideración social de las cantantes de ópera ${ }^{11}$ por encima de las instrumentistas ${ }^{12}$ desde entonces. Además, a finales del siglo XIX, y durante la cronología coincidente con el desarrollo vital y profesional de la protagonista de este artículo, las prima donna eran respetadas y admiradas, convirtiéndose en las verdaderas protagonistas del período:

\begin{abstract}
"De todas las mujeres intérpretes profesionales del siglo XIX, la mayoría eran cantantes. Las más destacadas fueron las que interpretaron ópera, pero muchas grandes vocalistas también participaron en conciertos públicos y en el contexto de la música religiosa. Las cantantes de ópera fueron las grandes estrellas de la época: enaltecidas y adoradas, tenían una reputación internacional y hicieron su aparición en teatros de ópera de toda Europa, así como en América del Norte y del Sur" (Reich, 1991, p. 165) ${ }^{13}$.
\end{abstract}

A pesar de que algunas cantantes del momento no contaban con conocimientos musicales y solían aprender de memoria un número determinado de óperas y obras musicales, Mercedes Capsir recibió una esmerada formación en el Conservatorio del Liceo de su ciudad natal. Posteriormente, en el año 1914 realizó su debut en el Gran Teatro del Liceo de Barcelona, enclave protagonista de este trabajo. Mientras Emilio Casares señala que su primera actuación en el citado teatro se produjo encarnando el papel de Micaela en Carmen (2002, p. 141) de Georges Bizet (1838-1875), Gonzalo Badenes, por su parte, señala que Capsir debutó dando vida al papel de Gilda en Rigoletto de Giuseppe Verdi (1813-1901), a pesar de que fue la ópera de Bizet la que catapultó al gran éxito a la debutante catalana: "Durante la temporada 1914-15 cantó el papel de Micaela en el Liceu, aunque sería el de Gilda el rol que la consagraría dentro del campo de lírico-ligera" (Badenes, 2005, p. 320).

\footnotetext{
10 "A number of women, most of whom grew up in families of professional artists or musicians, managed to force successful performing career in the early- and mid-19th century". En inglés original, traducido por la autora.

11 Para una profundización sobre la relación entre género y escena, véase el capítulo 5 del volumen Feminismo y música: introducción crítica (Ramos López, 2003).

12 "Debido a la larga tradición vocal femenina en el arte musical (sin mencionar la necesidad de voces de mujeres), el canto se consideraba una carrera socialmente más aceptada para una mujer música y muchas figuras femeninas desarrollaron una carrera rentable como cantantes de ópera o solistas" (Lumsden, 2010, p. 218). "Because of the long-standing female vocal tradition in art music (not to mention the need for female voices), singing was considered a more socially acceptable career for a female musician, and many women had profitable career as opera singers or soloists". En inglés original, traducido por la autora.

13 "Of all the professional women performers in the nineteenth century, the largest number were singers. Most prominent were those who sang opera, but many great vocalists also appeared in public concerts and church music. The opera singers were the great stars of the period: lionized and adored, they had international reputations and appeared in opera houses throughout Europe and North and South America". En inglés original, traducido por la autora.
} 


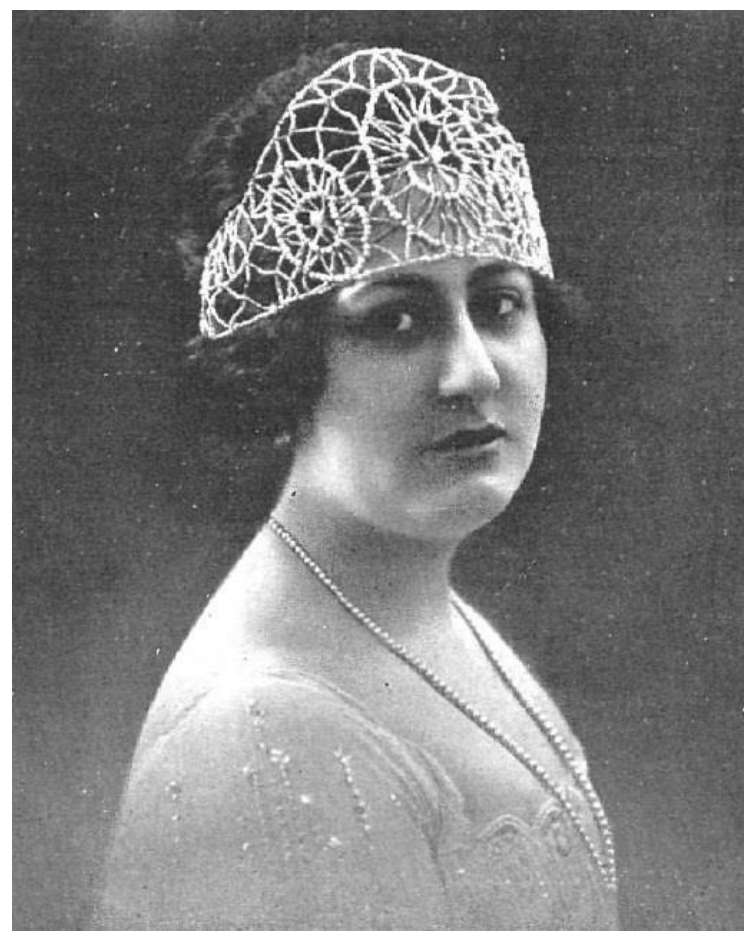

Figura 1. Mercedes Capsir.

Fuente: Colección Sánchez Rodríguez.

Tras subirse por primera vez a las tablas del Teatro Real de Madrid en 1916 -con gran éxito, interpretando el papel de Violetta en La traviata de Verdi-, entre otros espacios operísticos de referencia, dio el salto internacional con producciones en Lisboa, Buenos Aires y Santiago de Chile ese mismo año. En 1918, Mercedes Capsir hizo su presentación pública en la ciudad de Milán y, tras ese acto, gozó con presencia habitual en diferentes ciudades italianas, siendo el año 1922 especialmente fructífero al presentarse en el Teatro Dal Verme de Milán, en La Fenice de Venecia y en el Costanzi de Roma (Badenes, 2005, p. 320). Fue unos años después, en 1924, cuando debutó en el Teatro alla Scala con Rigoletto, compartiendo escenario con su compatriota Miguel Fleta (1897-1938) y bajo la dirección de Arturo Toscanini (1867-1957), quien la había solicitado para dicha función:

\footnotetext{
"Esta serie ininterrumpida de éxitos impulsó al temible Toscanini a requerir a nuestra soprano para una histórica producción de Rigoletto, en la Scala, en febrero de 1924. La noche del 13 de febrero, Capsir arrasó en un título que hasta entonces había detentado como propio la gran Toti dal Monte. Junto a Miguel Fleta y Carlo Galeffi, la Gilda de la soprano catalana marcó una época en el histórico coliseo milanés" (Badenes, 2005, p. 320).
}

Durante los años treinta continuó con una intensa agenda por diversas ciudades europeas -como Niza, Bruselas, Múnich, Budapest y Barcelona (Heilbron, s. f.), entre otras- y su última aparición pública en el ámbito operístico se produjo en el Liceo en 1949, interpretando Il matrimonio segreto de Domenico Cimarosa (1749-1801). Tras abandonar los escenarios, Capsir situó su domicilio en Italia, donde vivió hasta su fallecimiento en 1969 en la ciudad de Suzzara, próxima a Mantua. 


\title{
La ópera tras la contienda: La soprano Mercedes Capsir y el renacer del Gran Teatro del Liceo de Barcelona tras la Guerra Civil Española (1939)
}

Destacada "por la coloratura, su voz cristalina, el agudo y unas cualidades interpretativas sobresalientes" (Casares, 2002, p. 142), durante su carrera la soprano interpretó, esencialmente, un repertorio formado por aquellas óperas cuyas protagonistas presentan un registro de soprano ligera. Es el caso de La traviata, El barbero de Sevilla, Rigoletto y La Bohème, siendo esta última la primera obra que se pudo escuchar al finalizar la guerra en la ciudad condal y que es el núcleo del presente trabajo. Además, gracias a su vinculación a la industria fonográfica, ha sido posible continuar disfrutando de su arte a través de sus grabaciones de óperas, como Lucía de Lammermoor (1929), Rigoletto (1929), El barbero de Sevilla (1929), Marina (1929) y La traviata (1931), la mayor parte de ellas registradas en el Teatro alla Scala, a pesar de que su voz no contaba con un volumen significativo:

\begin{abstract}
"Celetti, entre otros críticos, subraya la adversa circunstancia de que la voz de Mercedes Capsir no fuese muy «fonogénica»., habida cuenta de los procedimientos de grabación de la época. Que esta voz, incluso con limitaciones, fue gobernada por una inteligente artista de primer orden lo demuestra la evolución experimentada por su repertorio, a lo largo de 35 años de carrera, y que sin embargo no impidió a la soprano cantar, casi hasta última hora, obras que figuraron en el mismo desde el principio" (Badenes, 2005, p. 322)
\end{abstract}

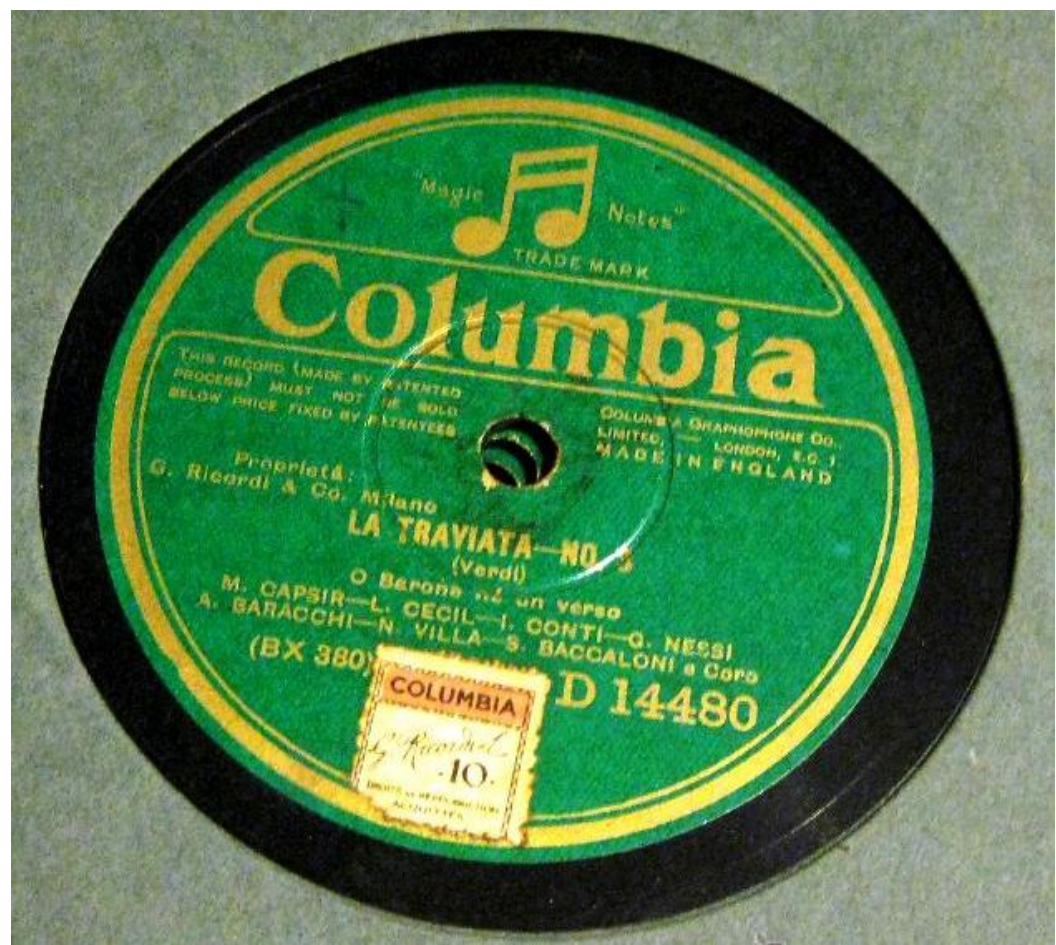

Figura 2. Ejemplar discográfico de La traviata (1931). Fuente: Colección Sánchez Rodríguez.

Conviene apuntar que Mercedes Capsir puede ser comprendida como parte de una generación de sopranos ligeras nacidas en Barcelona en fechas próximas y de gran éxito internacional, junto a Josefina Huguet (1871-1950), María Barrientos (1884- 


\section{Virginia Sánchez Rodríguez}

1946), Graziella Paretto (1889-1973) y Elvira de Hidalgo ${ }^{14}$ (1891-1980). Con todas ellas, Capsir coincide en haber sido representante de la coloratura -una técnica vocal que estaba menos en auge en la época hasta su desarrollo profesional-, en haber gozado de una exitosa carrera en el ámbito internacional y en la poca fortuna que todas ellas han sufrido en el recuerdo colectivo, sobre las que aún existen escasas investigaciones ${ }^{15}$. Pero, más allá de otras cantantes, la seleccionada para protagonizar la primera función de la nueva etapa del Gran Teatro del Liceo en 1939 fue Mercedes Capsir.

\section{Una función grandiosa y con tintes políticos}

El 29 de abril de 1939, el Gran Teatro del Liceo volvió a abrir sus puertas con este nombre tras la finalización de la Guerra Civil Española. Tal como hemos avanzado, la soprano Mercedes Capsir participó en la celebración de esta primera función en tiempos de paz. Benéfica y no exenta de tintes políticos, la gala contó con la presencia de un nutrido público formado por lo más granado de la sociedad barcelonesa y por un elevado número de militares, de acuerdo con el carácter del Régimen de Franco. Anunciada como "Extraordinaria función benéfico-patriótica", en concreto se ofreció la representación de La Bohème, de Giacomo Puccini (1858-1924). La célebre obra fue la elegida para esta importante cita por su popularidad, por su excelencia dentro del repertorio italiano y por responder al gusto de la burguesía local hacia la ópera italiana, de la misma forma que una ópera en la lengua de Dante también había sido el primer vestigio de este género representado en Barcelona dos siglos atrás ${ }^{16}$. De acuerdo con el evento protagonista de este trabajo, con la intención de lograr la mejor acogida posible por parte del público barcelonés, unos días antes de su celebración, fue anunciado en los medios de comunicación, como se puede constatar en La Vanguardia Española, con fecha de 20 de abril de 1939:

"El anuncio de celebrarse en nuestro primer teatro lírico, el sábado, día 29, por la tarde, una extraordinaria función de "Auxilio Social" y Hospital Clínico, organizada por la Sociedad de Propietarios y empresarios del Liceo, bajo el patronazgo del General Jefe de la Cuarta Región, General Álvarez Arenas, ha

\footnotetext{
14 Conviene apuntar que, a pesar de haber desarrollado una gran carrera performativa, las referencias historiográficas relativas a Elvira de Hidalgo principalmente tienen que ver, aunque de forma somera, en su labor como maestra de María Callas (1923-1977). En ese sentido, véase Stassinopoulos Huffington, 2002, pp. 37-40; Levine, 2003, p. 21.

15 Sobre María Barrientos, véase Sánchez Rodríguez, 2018a; Sánchez Rodríguez, 2018b, pp. 275-284; Sánchez Rodríguez, 2018c, pp. 313-334. Sobre Graziella Pareto, véase Pareto, 1992.

16 En el año 1705, se produjo la primera interpretación de una ópera en la ciudad de Barcelona. En concreto, tuvo lugar en el salón de la Lonja, siendo Il più bel nome de Antonio Caldara (1670-1736) la obra escogida. También fueron italianas la primera ópera representada en el Liceo tras su inauguración en 1847 -Anna Bolena de Gaetano Donizetti (1797-1848)-y la ópera seleccionada para la función de reapertura del Liceo en 1862 -I Puritani de Vincenzo Bellini (1801-1835)-, interpretada tras la necesaria reconstrucción por culpa del incendio sufrido el año anterior. Véase Sánchez Rodríguez, 2020, pp. 28-29.
} 


\section{La ópera tras la contienda: La soprano Mercedes Capsir y el renacer del Gran Teatro del Liceo de Barcelona tras la Guerra Civil Española (1939)}
despertado, como era de esperar, entusiasta acogida por nuestro público, siendo ya en gran cantidad el pedido de localidades.
La Bohème, la inspirada ópera de Puccini, tendrá por principales intérpretes a nuestra eximia diva Mercedes Capsir Tanzi, Carlos Merino, el célebre tenor de la Scala, de Milán, y el no menos célebre barítono Giovanni Inghilleri del Real, de Roma, que han aceptado con entusiasmo tomar parte en esta función patriótica benéfica.
Todos los elementos que actuarán en la obra, sin excluir los coros, orquesta, banda, maquinaria, dependencias, etc., han ofrecido su desinteresado concurso, renunciando a sus haberes.
El Liceo presentará, pues, el próximo día 29, por la tarde, el aspecto de las grandes solemnidades.
En la Administración del Gran Teatro se admiten encargos para la función, sin aumento de Contaduría" (La Vanguardia Española, Barcelona, 20/04/ 1939, p. 6).

El mismo día que la prensa se hacía eco, por primera vez, del evento -el 20 de abril de 1939-, los socios recibieron una carta dirigida por el presidente de la Sociedad del Gran Teatro del Liceo, Antonio Mercader Brunet, donde daba cuenta a los asociados de la celebración de la función, animándolos a su participación y a sus donativos del siguiente modo:

\footnotetext{
"Distinguido consocio:

Interpretando el sentir patriótico y humanitario de la Sociedad que me honro en presidir, la Junta de Gobierno de acuerdo con el Empresario de nuestro Gran Teatro y bajo el patronato de S. E. el General Jefe de la $4^{a}$ Región D. Eliseo Álvarez Arenas, ha organizado una extraordinaria representación de La bohème a beneficio de AUXILIO SOCIAL y del HOSPITAL CLÍNICO DE BARCELONA, que tendrá lugar el sábado día 29 de los corrientes a las seis de la tarde, contando para ello con el desinteresado y valioso concurso de Mercedes Capsir de Tanzi, Carlos Merino, Juan Inghilieri y otros prestigiosos elementos.

Cuantos intervendrán en la representación, orquesta, masa coral, maquinaria, electricistas, dependencias, etc. etc., lo harán asimismo desinteresadamente. Atendido que la mencionada función no disfruta subvención especial por parte de la Propiedad y teniendo en cuenta el fin benéfico que en la misma se persigue, esta Junta vería con sumo agrado honrase Vd. la fiesta con su presencia, contribuyendo además a tan humanitaria obra con el importe asignado a su localidad, la cual quedará a su disposición en la Mayordomía de este Gran Teatro hasta el 26 de los corrientes donde podrá recogerla todos los días laborales de 10 a 13 y de 16 a 18.

Transcurrido dicho plazo sin efectuarlo, se considerará que son cedidas, y se pasarán a la Comisión Organizadora para que proceda a su venta.

No dudando que la iniciativa de esta Junta tan felizmente acogida por S. E. el General Jefe de la $4^{\underline{a}}$ Región, secundada por la Empresa y por cuantos elementos de ella dependen, ha de merecer la entusiasta y unánime aprobación de todos los señores Accionistas, confiadamente espera esta Junta verla patentizada el día de la representación con su asistencia al acto, contribuyendo a la par en doble aspecto a las finalidades que con el mismo se persiguen en bien de las meritísimas Instituciones a que van destinados los beneficios que se obtengan, contribuyendo con ello a patentizar la adhesión y admiración al Glorioso Movimiento Nacional y a su invicto Caudillo el Generalísimo Franco.

El Presidente ac.
} 


\section{Virginia Sánchez Rodríguez}

Antonio Mercader Brunet"17.

Las jornadas previas a la función, la prensa se hizo eco también del éxito de reservas de entradas ${ }^{18}$ y recogió la satisfacción de los organizadores por el desarrollo de los preparativos:

"Satisfechos pueden estar los patriotas organizadores de esta magna fiesta en la que el divino arte, se asocia a un tan justo homenaje como el que se rendirá el próximo sábado por la tarde en nuestro primer teatro lírico.

Nuestro particular amigo señor Mestres, Director Artístico y empresario, y los señores de la Junta de Gobierno de la Sociedad del Gran Teatro del Liceo, están recibiendo constantes pruebas de adhesión y felicitación, por la magnífica y laboriosa labor que vienen realizando para que la función resulte un verdadero éxito.

El lleno que registrará nuestra hermosa sala de espectáculos está ya por descontado, ya que son muy pocas las localidades que ayer quedaban a la venta. Homenaje al glorioso Ejército Nacional, y a beneficio de instituciones tan beneméritas como "Auxilio Social" y Hospital Clínico, es el que el Liceo tributa en la función del sábado y en la que artistas de tan alto relieve como nuestra insigne compatriota Mercedes Capsir, Rosita Sanz, Carlos Merino, Ceprione Colombo, Manuel Gas, maestro Sabater, etc., forman el magnífico cuadro de artistas, y para orgullo y satisfacción de todos debemos hacer resaltar el rasgo digno de todo encomio, de que todos los elementos que directa o indirectamente toman parte en la función lo hacen absolutamente desinteresados.

Barcelona, pues, tendrá el sábado ocasión de patentizar a todos su favor y su aplauso" (La Vanguardia Española, Barcelona, 25/04/1939, p. 6).

La Vanguardia Española, un diario generalista de alcance nacional, con sede en Barcelona y único medio de este tipo que referenció el evento, continuó anunciando la función a modo de recordatorio en fechas más cercanas, siempre destacando su trascendencia. Especialmente, se señala que "el sábado próximo en función de tarde a las seis, nuestro primer Teatro lírico marcará una fecha gloriosa en los anales de su historia" (La Vanguardia Española, Barcelona, 26/04/1939, p. 4) y se subraya que, durante los días previos, las previsiones se habían "superado en la organización de esta magna fiesta benéfica patriótica, cuyos resultados, si bien se daban por descontado, han superado a todo cálculo" (La Vanguardia Española, Barcelona, 26/04/1939, p. 4).

\footnotetext{
${ }^{17}$ Documento 44078-003-03. Arxiu Històric de la Societat del Gran Teatre del Liceu. Recuperado de https://www.bib.uab.cat/human/arxiusocietatliceu/publiques/indexcat.php

18 "El enorme entusiasmo despertado por la gran fiesta patriótica benéfica, y de Homenaje a nuestro glorioso Ejército Nacional, ha quedado plenamente confirmado, por el gran pedido de localidades, en el que figura el «todo Barcelona».

Nuestra insigne Diva Mercedes Capsir Tanzi, con sus admirados colaboradores, han telegrafiado su llegada a ésta para el próximo martes.

Es merecedor de todo elogio, el gesto de todos cuantos toman parte en la representación, que han renunciado en absoluto a sus haberes, con el fin de que los ingresos íntegros se destinen a las patrióticas instituciones benéficas.

El sábado, pues, nuestro primer teatro lírico vestirá sus mejores galas y señalará una gloriosa fiesta patriótica y benéfica" (La Vanguardia Española, Barcelona, 22/04/1939, p. 6).
} 


\section{La ópera tras la contienda: La soprano Mercedes Capsir y el renacer del Gran Teatro del Liceo de Barcelona tras la Guerra Civil Española (1939)}

El mismo día de la función, un par de representantes de la Junta del Gran Teatro del Liceo, Joan Mestres y Carlos Rabassó -quien fuera vicepresidente del espacio teatral y quien había sido el representante de la Sociedad en la recepción de Capsir y otros artistas en el puerto ${ }^{19}$-, ofrecieron una visita al alcalde ${ }^{20}$, acompañados de algunas de las grandes figuras que participarían en la producción, siendo Mercedes Capsir el centro de atención. Así, con este encuentro con las instituciones públicas, se demostraba la implicación de todos los participantes y la legitimación sociopolítica de la función.

Tras los minuciosos preparativos y la excelente publicidad, la reapertura del Liceo tuvo lugar el 29 de abril de 1939, a las 6 de la tarde. La soprano española fue la gran estrella de la función, como se puede constatar también por el mayor tamaño de la tipografía utilizada para plasmar su nombre en el programa de mano y por ser la única de los intérpretes cuyo retrato se incluyó en el mencionado programa (Figura $3)$.

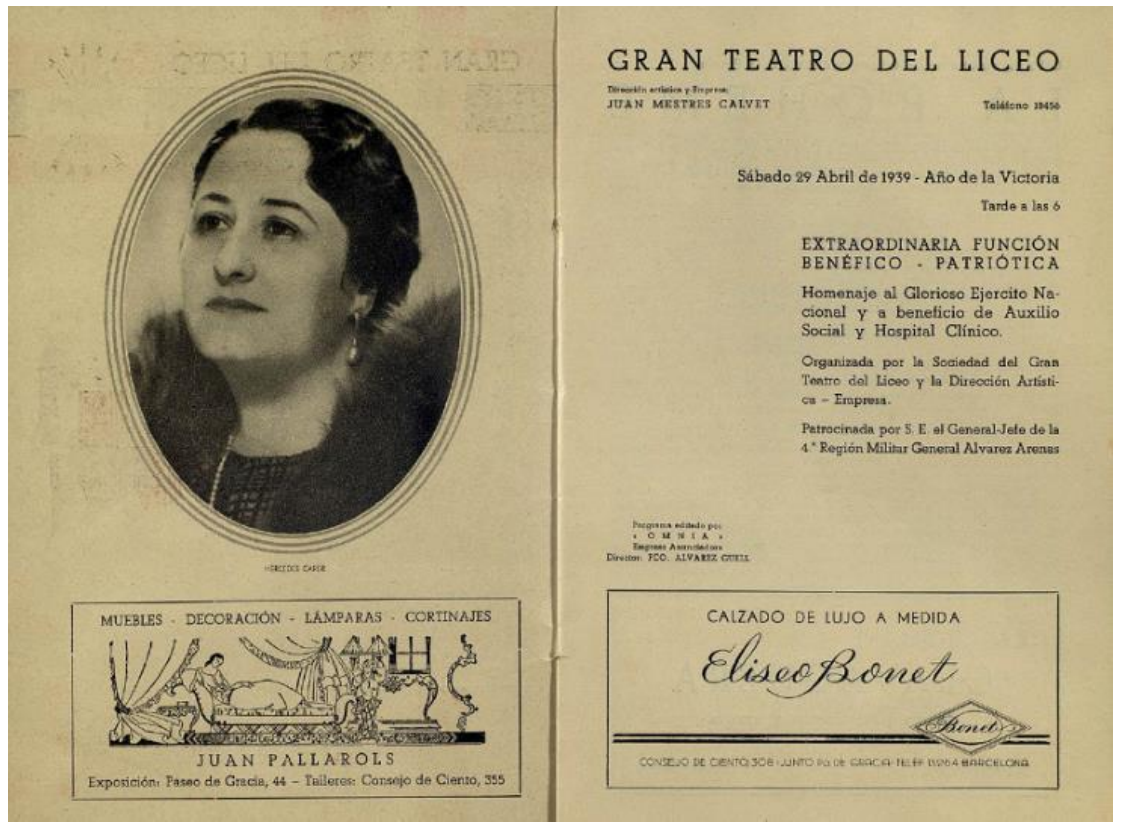

Figura 3. Retrato de Mercedes Capsir en el programa de mano, pp. 2-3. Fuente: Colección Sánchez Rodríguez.

\footnotetext{
19 "Esta Sociedad del Gran Teatro del Liceo delega al Miembro de su Junta Don Carlos Rabassó Soler para que le represente en la recepción de los artistas Mercedes Capsir y otros señores que llegan en el vapor FIRENZE procedentes de Italia para asistir a la función benéfica patrocinada por el Excmo. Sr. General Jefe de la 4⿳亠丷厂 Región Militar, a beneficio de Auxilio Social y Hospital Clínico.

Esperamos de las Autoridades del puerto que no pondrán dificultades al cumplimiento de dicha misión.

Barcelona 26 de abril de 1939.

Año de la Victoria.

El Presidente ac.". Documento 44078-003-23. Arxiu Històric de la Societat del Gran Teatre del Liceu. Recuperado de https://www.bib.uab.cat/human/arxiusocietatliceu/publiques/indexcat.php

20 "En representación de la Junta del Gran Teatro del Liceo el empresario señor Mestres Calvet y don Carlos Rabassó han visitado al alcalde, acompañando a la eminente artista señora Capsir y los señores Carlos Merino y Ciprione Colombo, quienes interpretarán La Boheme, en función que, bajo el alto Patronato del General de la Cuarta Región don Eliseo Álvarez Arenas, se celebrará hoy, a beneficio del Hospital Clínico y Auxilio Social" (La Vanguardia Española, Barcelona, 29/04/1939, p. 5).
} 


\section{Virginia Sánchez Rodríguez}

Capsir compartió escenario con otras figuras consagradas de la ópera. Es el caso del tenor chileno Carlos Merino21, quien había compartido funciones con Capsir previamente en el Liceo en Rigoletto, también junto al barítono italiano Mario Basiola (1892-1965) el 22 de diciembre de 1935 (La Vanguardia Española, Barcelona, 21/12/1935, p. 4). También tomaron parte de la función el barítono Colombo Ciprione, la soprano Rosa Sanz -que había debutado en el Teatro Olympia de la ciudad condal interpretando el papel de Gilda en Rigoletto (La Vanguardia Española, 31/12/1935, p. 13)- y Manuel Gas (1905-1995) -que destacó igualmente como actor y como intérprete lírico en zarzuelas y óperas-.

Todos los intérpretes trabajaron bajo la dirección de José Sabater (1882-1969), quien desarrolló una destacada carrera especialmente al frente de la orquesta del Gran Teatro del Liceo, donde ejerció como director titular durante cuatro décadas desde 1913- y que fue un conocedor en profundidad de la ópera. Así lo señala el compositor Xavier Montsalvatge (1912-2002) en el obituario publicado en La Vanguardia Española tras el fallecimiento de Sabater: "pocos músicos ha tenido Cataluña que, como José Sabater, conocieran tan a fondo el teatro musical y acumularon tanto saber y experiencia en un campo difícil y en nuestro país tan limitado como el de la ópera" (Montsalvatge, 12/08/1969, p. 21).

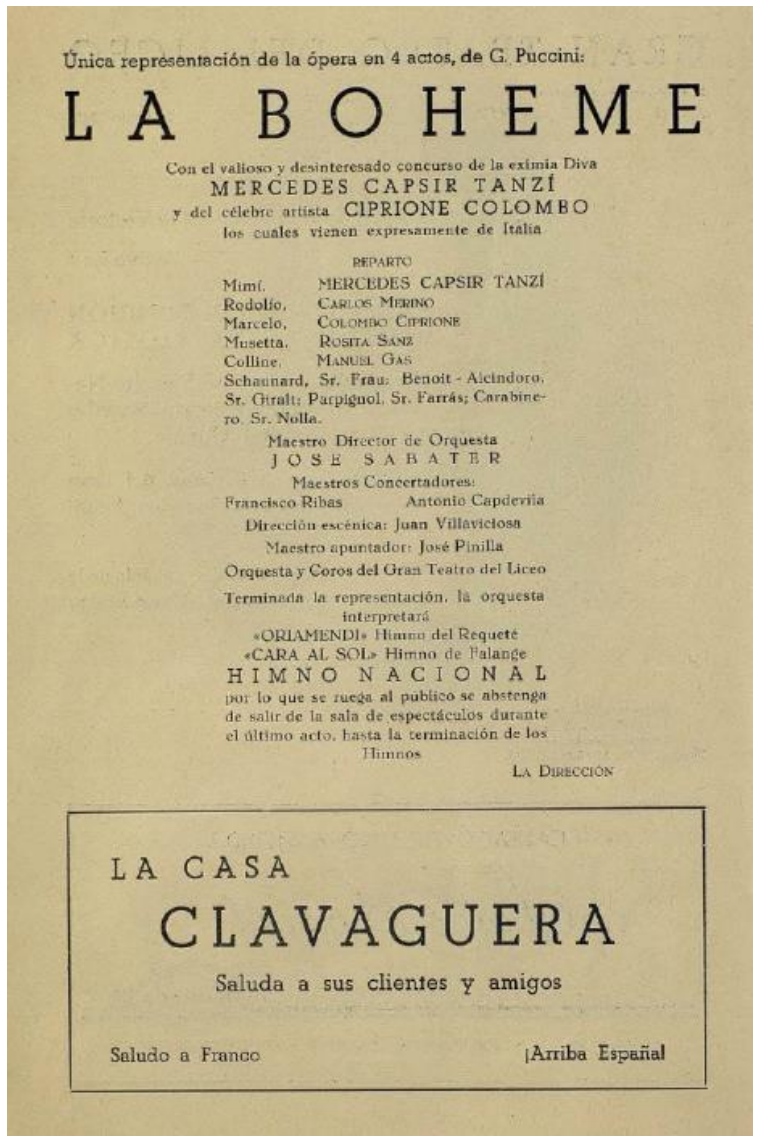

Figura 4. Programa de mano de la función, p. 4. Fuente: Colección Sánchez Rodríguez.

${ }^{21}$ Quien, en algunas ocasiones, era presentado con su nombre italianizado, Carlo Merino. 


\section{La ópera tras la contienda: La soprano Mercedes Capsir y el renacer del Gran Teatro del Liceo de Barcelona tras la Guerra Civil Española (1939)}

La función logró un arrollador éxito por parte del numeroso y selecto público formado igualmente por autoridades militares, autoridades civiles, socios y otros asistentes, habiendo abonado todos ellos el precio de sus entradas, como se puede constatar en la documentación conservada en el Archivo Histórico del Gran Teatro del Liceo (Arxiu Històric de la Societat del Gran Teatre del Liceu)-, que ocupó las dos mil quinientas ${ }^{22}$ localidades del Liceo, fruto del interés de la ópera de Puccini, de la calidad musical de sus intérpretes y de la solidaridad del pueblo barcelonés. La fortuna del evento se puede comprobar a través de la crítica y también por la cantidad recaudada, pues, según el "Resumen de ingresos y gastos" del evento, conservado en el Archivo Histórico de la Societat del Gran Teatre del Liceu, la cantidad líquida para hacer entrega a Auxilio Social y el Hospital Clínico ascendió a $27.624,85$ pesetas por la venta de localidades y los donativos recibidos ${ }^{23}$. Algunos de los miembros de la Sociedad, para contribuir, además de ofrecer un donativo, pusieron a disposición del Teatro sus localidades para que pudieran ser vendidas $\mathrm{y}$, de ese modo, aumentar la recaudación ${ }^{24}$.

Ahora bien, el evento destacó igualmente por razones artísticas y políticas. Esa circunstancia ya se observa, documentalmente, en el programa de mano del evento. La portada acapara un retrato de Francisco Franco en el centro, justo al lado del escudo de España durante el franquismo, caracterizado por añadir al escudo tradicional, además de otros motivos heráldicos tomados del estado de los Reyes Católicos -como el águila de San Juan o el yugo y las flechas- y una cartela con el lema «Una Grande Libre», entre otros elementos (Figura 5).

\footnotetext{
22 "La cabida de este Gran Teatro es de unas dos mil quinientas personas". Documento 44078-00302, con fecha de 24 de abril de 1939. Arxiu Històric de la Societat del Gran Teatre del Liceu. Recuperado de https://www.bib.uab.cat/human/arxiusocietatliceu/publiques/indexcat.php ${ }^{23}$ Los ingresos alcanzaron un total de $42.113,10$ pesetas -correspondientes con la venta de localidades y con los donativos recibidos- frente a los gastos de 14.488,25 pesetas. Documento 44078-003-32. Arxiu Històric de la Societat del Gran Teatre del Liceu. Recuperado de https://www.bib.uab.cat/human/arxiusocietatliceu/publiques/indexcat.php

${ }^{24}$ Un ejemplo de ello lo representa el socio Juan Framis Manen, que, en una carta de 26 de abril de 1939 dirigida al Sr. Presidente de la Sociedad del Gran Teatro del Liceo, le expone lo siguiente:

"Muy Sr. Mío y consocio; En contestación a su atta. dándome conocimiento de la representación a beneficio de Auxilio Social y del Hospital Clínico, pláceme anunciarle que pueden vender mis dos localidades y su importe, junto con 50 pesetas que tengo el gusto de adjuntarle con la presente, destinarlas al citado beneficio.

Le saluda atentamente su s.s.

Framis Manen". Documento 44078-003-28. Arxiu Històric de la Societat del Gran Teatre del Liceu. Recuperado de https://www.bib.uab.cat/human/arxiusocietatliceu/publiques/indexcat.php
} 


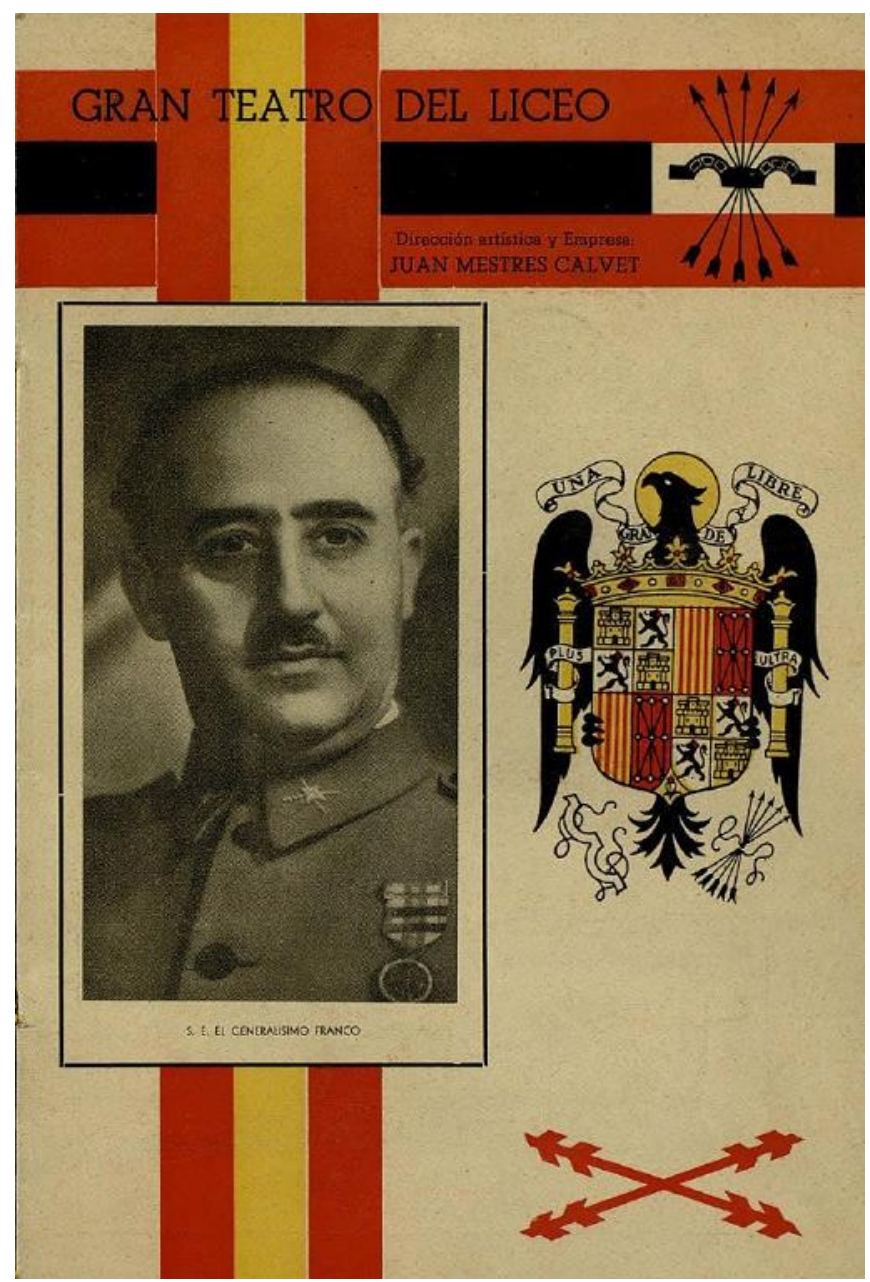

Figura 5. Programa de mano, portada. Fuente: Colección Sánchez Rodríguez.

Asimismo, conviene subrayar que el acto había sido concebido como un homenaje al Glorioso Ejército Nacional y a beneficio de Auxilio Social y Hospital Clínico, que fue organizado por la Sociedad de Propietarios y empresarios del Liceo y que contó con el patronazgo del General-Jefe de la Cuarta Región Militar del momento, el General Eliseo Álvarez Arenas. Así lo recoge U. F. Zanni, crítico de La Vanguardia Española, en su reseña publicada el día después de la función:

"Una vez más el arte se ha puesto al servicio de la Patria y de la Beneficencia. En el Liceo, por laudable iniciativa de la Junta de propietarios y del director artístico y empresario del Gran Teatro, don Juan Mestres Calvet, se celebró ayer tarde, patrocinada por el General-Jefe de la Cuarta Región Militar, don Eliseo Álvarez Arenas, una función que, además de atender a incrementar los ingresos para "Auxilio Social" y el Hospital Clínico, tenía el carácter de homenaje al invicto Ejército Nacional.

Con esta fiesta, el Liceo recobraba la alta jerarquía artística de que había quedado desposeído durante el omnioso dominio rojo.

No hay que decir, por ocioso, que Barcelona entera se hallaba representada en el Liceo, deseosa, tanto de sumarse a un acto de sincero altruismo y de cálida exteriorización patriótica, como de expresas su íntimo gozo por ver de nuevo envuelto en el prestigio el teatro que es legítimo orgullo de los españoles. 


\section{La ópera tras la contienda: La soprano Mercedes Capsir y el renacer del Gran Teatro del Liceo de Barcelona tras la Guerra Civil Española (1939)}

En la organización del espectáculo, que recordó los mejores tiempos liceístas, se pudo apreciar la alta inteligencia y el buen gusto del empresario, señor Mestres, quien desde los primeros instantes del Movimiento se sumó a la causa del Generalísimo, sufriendo por ello no pocos quebrantos de fortuna, sobre la que se cebó la rapiña roja.

Como prueba de afecto hacia Italia, nación hermana que ha sabido comprender la nobleza de los ideales del Caudillo, se puso en escena La Bohème, la famosa ópera de Puccini, cuyas suaves e inspiradas melodías y cuyo atrayente romanticismo musical y teatral la mantiene, aún al correr de los años, en el sincero favor de los públicos" (Zanni, 30/04/1939, p. 3).

No era una casualidad que una ópera italiana fuera la obra seleccionada para inaugurar la nueva temporada del Liceo, pues, recordemos, el repertorio italiano siempre gozó de una excelente acogida por el público barcelonés. Pero, en esta ocasión, además, una ópera del legado pucciniano, La Bohème, por su nacionalidad, era presentada como un reflejo de la buena sintonía entre el recién instaurado Régimen español y la dictadura de Benito Mussolini (1883-1945) en Italia. Recordemos la estrecha colaboración italiana al bando nacional durante la guerra civil: “Según Nenni, en España lucharon 120.000 soldados italianos (...). En la guerra española, los italianos formaron unidades completas bajo el mando exclusivo de sus propios generales (Roatta, Bastico y Gambara, sucesivamente" (Tamames, 1981, p. 249).

La crítica de Zanni acogió excelentes comentarios sobre el buen hacer de los intérpretes en la producción, destacando, por encima de todos, a Mercedes Capsir, una de las grandes artistas españolas que triunfaba por el mundo y que había regresado de Milán, su domicilio del momento, para tomar parte de esta función. Además de la belleza, la pureza y la maleabilidad de su voz, junto a sus grandes dotes dramáticas, en la crítica se recoge la supuesta adscripción ideológica de Capsir al nuevo Régimen:

\footnotetext{
“De entre los intérpretes que, sin excepción, se brindaron espontánea y generosamente a coadyuvar en el éxito artístico y económico de la fiesta, destacó notablemente Mercedes Capsir, la ilustre diva española, plenamente identificada con nuestra Cruzada, como lo tiene bien demostrado, y que, para encargarse del papel de Mimí no ha dudado un momento en abandonar su residencia de Milán, en la que, junto con el cónsul de España en aquella ciudad, señor Martínez Marello; el Jefe de Falange, don José Flores y otras personalidades, festejó con todo entusiasmo el triunfo definitivo del glorioso Ejército Nacional.

Clamorosamente triunfal fue también para Mercedes Capsir la jornada de ayer. Como otras veces, como siempre, Mercedes Capsir se impuso a la admiración del auditorio por la pureza de su voz, límpida, ágil, extensa: por su maestría de cantante, por su fina sensibilidad artística y por su fidelidad interpretativa.

¡Con qué convincentes acentos dijo el relato del primer acto! ¡Qué emoción puso en las frases del tercero! ¡Qué impresionantes acentos brotaron de su privilegiada gargantas en las escenas del acto postrero!

La concurrencia ovacionó insistentemente a la insigne artista, intensificando todavía más sus ovaciones cuando, al final del acto tercero, unas gentiles camaradas de "Auxilio Social" la ofrendaron varios cestos de flores" (Zanni, 30/04/1930, p. 3).
} 


\section{Virginia Sánchez Rodríguez}

Asimismo, en lo que respecta a la música, la adscripción ideológica del acto se puede constatar especialmente tras la interpretación de la ópera. Y es que la función concluyó con la interpretación de varios himnos, concretamente el "Oriamendi" -el himno del Carlismo -, el "Cara al sol" -el himno de Falange- y el Himno Nacional, tal como se señala en el programa de mano (Figura 4), donde, además, se solicita que el público se mantenga en la sala hasta la interpretación de los cantos patrióticos, una costumbre que se mantuvo al final de todos los espectáculos en el coliseo durante el franquismo (Fabre 2003, 213). Como podemos imaginar, la prensa del momento no solo señala la gran acogida de La Bohème sino, además, los clamores a estas melodías: "Los himnos provocaron explosiones de patriótico entusiasmo, mezclándose con los aplausos los fervorosos vítores a Franco y a España, Una, Libre y Grande" (Zanni, 30/04/1930, p. 3).

No olvidemos que esta forma musical, el himno, está repleta de una evidente carga semántica e ideológica, un testimonio que demuestra la vinculación de la música y la identidad nacional. Al fin y al cabo, el himno ${ }^{25}$ es "un símbolo que pone en juego los sentimientos subjetivos y la emoción individual y colectiva, contribuye de una manera decisiva a la construcción -o no- de una identidad nacional" (Nagore Ferrer, 2011, p. 827).

El año siguiente, Mercedes Capsir volvió al Gran Teatro del Liceo de Barcelona, ya como parte de la temporada habitual gestada, en tiempo récord, gracias a la gran implicación de Mestres, su director artístico. En esta ocasión, la función ofrecida el día 4 de enero de 1940 comprendió la interpretación de Madama Butterfly, también de Puccini. Se trataba de la primera vez que se ofrecía esta ópera en italiano en el Liceo (La Vanguardia Española, Barcelona, 05/01/1940, p. 4) y era, además, la primera vez que Capsir daba vida a la protagonista, Cio-Cio-San, en una actuación que, como era de esperar, logró un gran éxito. Especialmente, la crítica al evento destacó que "la voz luminosa, matizada, de acariciadoras inflexiones, igual de timbre, variada de color, de Mercedes Capsir se ajustó admirablemente a todas las gamas del sentimiento, desde la ingenua alegría hasta los más angustiosos desánimos" (La Vanguardia Española, Barcelona, 05/01/1940, p. 4).

Durante el segundo entreacto de la actuación, varios tenientes de alcalde de Barcelona de la legislativa de Miguel Mateu y Pla (1898-1972) -José Bonet del Río (1889-1965), Aurelio Joaniquet (1895-1963), Juan Ventosa (1879-1959) y Carlos de Montoliu y de Durán (1910-1976), barón de Albi-, varios concejales -Carlos Trías (1918-1969), Raimundo Frouchtman (1906-1987) y Domingo Castellar ( $¿$ ?-1955)y el jefe de ceremonial del ayuntamiento -Manuel Ribé (1878-1961)- se subieron a las tablas del teatro para hacer entrega a Mercedes Capsir de la notificaba por la que se le comunicaba que había sido distinguida con la Medalla de oro de la ciudad de Barcelona "por sus méritos artísticos y por sus reiteradas pruebas de acrecentado españolismo" (La Vanguardia Española, Barcelona, 05/01/1940, p. 4). Conviene

25 Para una profundización sobre el valor social y musical de los himnos, véase Fernández de Latorre Moreno, 2000; Alegre, 2008. 


\section{La ópera tras la contienda: La soprano Mercedes Capsir y el renacer del Gran Teatro del Liceo de Barcelona tras la Guerra Civil Española (1939)}

apuntar que, además de Capsir y los señores Bossi y Briasco, también recibió una medalla de Barcelona el propio Franco ${ }^{26}$. La soprano siempre fue una embajadora de España a través a su carrera internacional, pero, probablemente, sus desvelos e implicación en la primera función ofrecida en el Gran Teatro del Liceo en tiempos de paz del 29 de abril de 1939 también habrían podido ser determinantes para recibir esta distinción nacional.

\section{Conclusiones}

Tal como hemos expuesto, el día 29 de abril de 1939 la ciudad de Barcelona volvió a disfrutar de la ópera en el Gran Teatro del Liceo, nacido para acoger repertorio escénico, gracias a una función benéfica protagonizada por una de las sopranos españolas más célebres del momento, Mercedes Capsir. En este trabajo se ha presentado el estudio de un evento performativo protagonizado por la mencionada soprano como reflejo de las circunstancias sociales y políticas de España al finalizar la Guerra Civil. A este respecto, no se ha pretendido profundizar en su carrera, sino, más bien, rescatar el nombre y la relevancia de una de las muchas mujeres olvidadas de la historiografía y acercarnos a un acontecimiento histórico -como esta primera función en el Liceo tras la contienda- a partir de su presencia y actuación. Es decir, más allá de la labor específica de Capsir -que ya gozaba de aclamación internacional por su calidad musical-, la aproximación al evento desde un caso biográfico nos ha permitido la reconstrucción de algunos aspectos clave del contexto sociocultural de la sociedad barcelonesa en un momento histórico concreto, justo después de la proclamación de la victoria por parte del bando nacional encabezado por Francisco Franco 27.

Las fuentes institucionales y hemerográficas consultadas hablan del éxito de la función extraordinaria. Si bien es cierto que debemos tener cautela con el trabajo histórico en torno a cualquier fuente gestada bajo un régimen dictatorial, desde el punto de vista artístico, las crónicas contenidas en La Vanguardia Española -el único medio de alcance nacional que referenció el evento- permiten afirmar que el acto se celebró por todo lo alto y que se caracterizó por los exquisitos preparativos de la Sociedad del Gran Teatro del Liceo, por el buen trabajo organizativo de Joan Mestres en la gestión de este acto inaugural -aperitivo de la temporada operística 19391940 que estaba próxima a celebrarse- y por el buen hacer de los músicos implicados.

\footnotetext{
26 "Aprobar la factura de Federico Marés, de importe 8.400 ptas., por cuatro medallas de la Ciudad de oro y plata. para S. E. el Generalísimo Franco, señora Capsir y señores Comm. Carlo Bossi y Jean Briasco, con cargo a la part. $6 \mathrm{r}$ del actual régimen económico transitorio (Gaceta Municipal de Barcelona, Barcelona, 24/02/1941, p. 65).

${ }^{27}$ A pesar de las diferencias geográficas respecto del estudio de caso presentado en este artículo, véase, por su interés metodológico, la contribución de Silvina Martino por presentar el análisis de un contexto sociocultural a partir, en su caso, de la historia de vida de una cantante lírica argentina, Juana Capella (Martino, 2019, pp. 73-89.).
} 


\section{Virginia Sánchez Rodríguez}

Igualmente, también debemos apuntar la existencia de tintes políticos en la función, algo que se observa a través de la simbología integrada en el acto a través de la música -el himno del Carlismo, el himno de Falange y el Himno Nacional-, del elevado número de políticos y militares asistentes, de los símbolos franquistas integrados en el programa de mano del evento y de los testimonios de la prensa. De hecho, en todas las noticias periodísticas, así como en la reseña posterior a la función, no solo se incluyeron notificaciones de carácter publicitario sino también loas a la grandeza del recién proclamado Régimen a través de la celebración de un evento cultural de tales dimensiones. Esta forma de proceder es un avance de la utilización de la cultura -en este caso, una representación operística- como vehículo ideológico controlado por los postulados del gobierno (Tusell, 1997, p. 102), una característica del franquismo. Y es que la carga política en este evento ya anticipa la utilización institucional de la música que, posteriormente, haría durante la España de Franco 28 .

Conviene subrayar que la selección del repertorio interpretado, La bohème, no fue arbitraria, de la misma forma que la elección de Mercedes Capsir como gran estrella de la actuación también habría sido algo meditado. Según las fuentes hemerográficas expuestas, Capsir sería afín a los postulados gubernamentales, algo que, junto a su fama, su bella y maleable voz y su perfección técnica, la hizo protagonista de esta función benéfica y merecedora de la Medalla de Oro de la ciudad de Barcelona en 1940. Ahora bien, independientemente de cuestiones políticas, cabe destacar que la función protagonista de este estudio destacó por su carácter benéfico, por la calidad musical, por la gran acogida del público y por el éxito de la crítica, que, especialmente, se deshizo en halagos a Mercedes Capsir, una de las sopranos españolas más célebres del momento sobre quien conviene continuar investigando.

\section{Bibliografía}

Alegre, M. A. (coord.) (2008). El himno como símbolo político. León: Universidad de León.

Alier Axiala, R. (1986). El gran Teatro del Liceo. Madrid: Daimon.

Alier Axiala, R. (1990). L'òpera a Barcelona: orígens, desenvolupament i consolidación de l'ópera com a espectacle teatral a la Barcelona del siecle XVIII. Barcelona: Institut d'Estudis Catalans, Societat Catalana de Musicología.

\footnotetext{
${ }^{28}$ Para una profundización sobre la utilización política de la disciplina musical, véanse, entre otros trabajos, Muñiz Velázquez, 1998, pp. 343-363; Pérez Zalduondo, 2006, pp. 145-156; Piñeiro Blanca, 2013, pp. 237-262.
} 


\section{La ópera tras la contienda: La soprano Mercedes Capsir y el renacer del}

Gran Teatro del Liceo de Barcelona tras la Guerra Civil Española (1939)

Alier Axiala, R. (1994). El gran Teatro del Liceo. Barcelona: Francesc X. Mata.

Alier Axiala, R. (2011). Historias de la historia de la ópera. Teià, Barcelona: Ma Non Troppo.

Arañó, L. \& Capdevila, M. (2019). Topografia de la destrucció. Els bombardeigs de Barcelona durant la Guerra Civil (1936-1939). Barcelona: Ajuntament de Barcelona, Fundación Carles Pi i Sunyer.

Badenes, G. (1994). Mercedes Capsir. Ritmo 65(654), pp. 50-51.

Badenes, G. (2005). Voces (Ritmo, 1987-2000). Valencia: Universitat de València.

Celleti, R. (1992). Capsir, Mercedes [Mercè]. En S. Sadie (ed.). The New Grove Dictionary of Opera, vol. 1. Londres: MacMillan, p. 723.

Ezquerro Esteban, A. \& Ezquerro Guerrero, C. (2018). Barcelona y la música de moda. De lo finisecular decimonónico a comienzos del siglo XX (nuevos bailables y llegada del jazz). El caso de Clifton Worsley (*1873; †1925). Parte I. Una biografía en su contexto. Cuadernos de Investigación Musical (5), pp. 5-98.

Ezquerro Esteban, A. \& Ezquerro Guerrero, C. (2019). Barcelona y la música de moda. De lo finisecular decimonónico a comienzos del siglo XX (nuevos bailables y llegada del jazz). El caso de Clifton Worsley $(* 1873 ;$ †1925). Parte II. Una obra original, hija de su tiempo. Cuadernos de Investigación Musical (7), pp. 161-232.

Ezquerro Esteban, A. (2020). El músico barcelonés Rafael Guardia, «del comercio» (Relaciones familiares, empresariales y profesionales en la edición musical desde la exposición universal de 1888 hasta comienzos del siglo XX). Cuadernos de Investigación Musical (9), pp. 106-156.

Fabre, J. (2003). Els que es van quedar: 1939: Barcelona, ciutat ocupada. Barcelona: Publicacions de l'Abadia de Montserrat.

Fernández de Latorre Moreno, R. (2000). Historia de la música militar de España. Madrid: Ministerio de Defensa.

Fernández-Cid, A. (1974). Voces de oro en el Gran Teatro del Liceo: Feodor Chaliapin, Conchita Supervia, Mercedes Capsir; por cortesía de J. A. Pàmias (Gran Teatro del Liceo). Ritmo 45(447), pp. 26-27. 


\section{Virginia Sánchez Rodríguez}

Heilbron, M. (s.f.). Mercedes Capsir Vidal. Real Academia de la Historia. Recuperado de http://dbe.rah.es/biografias/10573/mercedes-capsir-vidal

Hernández Girbal, F. (1988). Mercedes Capsir. Ritmo 59(589), p. 109.

Lauri-Volpi, G.(1974). “Mercedes Capsir, tierna, convincente "Mimí”: Las grandes voces de la lírica contemporánea [Torregrosa Valero, Manuel (trad.)]. Ritmo 44(440), p. 4.

Levine, R. (2003). Maria Callas: A Musical Biography. New York: Black Dog \& Leventhal Publishers.

Lumsden, R. (2010). Women's Leadership in Western Music Since 1800. En K. O'Connor (ed.). Gender and Women's Leadership. A Reference Handbook, volume 2, pp. 917-925. Los Angeles: SAGE Publications.

Martínez del Campo Saucedo, L. (1998). Manifestaciones culturales de Barcelona (influencias en la Ceremonia Inaugural de los XXV Juegos Olímpicos de 1992. En J. Esteinou Madrid (coord.). Espacios de comunicación 3, pp. 423-432. México: Universidad Iberoamericana.

Martino, S. (2019). La soprano Juana Capella. Primeros apuntes para una historia de la interpretación vocal femenina operística en la Argentina de inicios del siglo XX. Revista del IIMCV 33(2), pp. 73-89.

Montsalvatge, X. (12/08/1969). Ha muerto el maestro José Sabater. La Vanguardia Española, p. 21.

Muñiz Velázquez, J. A. (1998). La música en el sistema propagandístico franquista. Historia y comunicación social 3, pp. 343-363.

Nagore Ferrer, M. (2011). Historia de un fracaso: el "Himno nacional" en la España del siglo XIX. Arbor: Ciencia, Pensamiento y Cultura (751), pp. 827-845.

De la Ossa Martínez, M. A. (2009). La música en la guerra civil española (Tesis Doctoral). Cuenca: Universidad de Castilla-La Mancha.

Pareto, L. (1992). Graziella Pareto. Barcelona: Labor.

Pérez Zalduondo, G. (2006). Ideología y política en las instituciones musicales españolas durante la segunda república y primer franquismo. Quintana (5), pp. 145156. 


\section{La ópera tras la contienda: La soprano Mercedes Capsir y el renacer del Gran Teatro del Liceo de Barcelona tras la Guerra Civil Española (1939)}

Piñeiro Blanca, J. (2013). Instrumentalización política de la música desde el franquismo hasta la consolidación de la democracia en España. Revista del CEHGR (25), pp. 237-262.

Piñero, C. C. (2004). Mujer y música clásica: el largo camino hacia la plena participación. En J. Cruz \& B. Zecchi (eds.). La mujer en la España actual: ¿evolución o involución?, pp. 397-412. Barcelona: Icaria.

Radigales, J. (1998). Els orígens del Gran Teatre del Liceu (1837-1847): de la plaça de Santa Anna a la Rambla: historia del Liceu Filharmònic d'Isabel II o Liceu Filodramàtic de Barcelona. Barcelona: Abadía de Montserrat.

Radigales, J. (1999). Representacions operístiques a Barcelona (1837-1852): l'eclosió teatral a partir de la prensa: l'evolució del gust en el públic del segle XIX: nous valors de la lírica a partir de la crítica. Barcelona: Universitat de Barcelona.

Ramos López, P. (2003). Feminismo y música: introducción crítica. Madrid: Narcea.

Ramos López, P. (2013). Una historia particular de la música: la contribución de las mujeres. Brocar 37, pp. 207-223.

Reich, N. B. (1991). European Composers and Musicians, ca. 1800-1890. En K. Pendle (ed.). Women \& Music: A History, pp. 147-174. Bloomington: Indiana University Press.

Sánchez Rodríguez, V. (2018a). La soprano María Barrientos y sus epístolas de juventud (1905-1906). Málaga: Universidad de Málaga.

Sánchez Rodríguez, V. (2018b). La Metropolitan Opera House canta con voz española: la génesis neoyorquina de la soprano María Barrientos. Anuario Musical (73), pp. 275-284.

Sánchez Rodríguez, V. (2018c). María Barrientos y sus inicios fonográficos. Cuadernos de Investigación Musical (6) [no extraordinario, ejemplar dedicado a Estudios sobre el Patrimonio Musical Hispánico], pp. 313-334.

Sánchez Rodríguez, V. (2020). Capsir en la nueva etapa del Liceu después de la Guerra Civil. Ópera Actual (234), pp. 28-29.

Stassinopoulos Huffington, A. (2002). Maria Callas. The Woman Behind the Legend. New York: Cooper Square Press.

Tamames, R. (1981). Historia de España Alfaguara, v. 7. Madrid: Alianza. 


\section{Virginia Sánchez Rodríguez}

Tanzi Capsir, M. L.(2002). Mercè Capsir. Barcelona: Infiesta.

Tusell, J. (1997). Manual de Historia de España. Madrid: Historia 16.

Zanni, U. F. (30/04/1939). Gran Teatro del Liceo. La brillantísima función benéficopatriótica de ayer tarde. Fue representada La Boheme, obteniendo un gran éxito Mercedes Capsir. La Vanguardia Española, p. 3.

\section{Prensa}

Gaceta Municipal de Barcelona, Barcelona.

La Vanguardia, Barcelona.

La Vanguardia Española, Barcelona.

\section{Archivos}

Arxiu Històric de la Societat del Gran Teatre del Liceu. Barcelona. Disponible en https://www.bib.uab.cat/human/arxiusocietatliceu/publiques/indexcat.php [acceso: 18 de diciembre de 2019].

Colección Sánchez Rodríguez. Peñaranda de Bracamonte, Salamanca (Colección privada).

Recibido: 24/03/2020

Evaluado: 30/06/2020

Versión Final: 28/07/2020 